\title{
Managing LearningThrough Mathematical Literacy Based on Cognitive Load
}

\author{
Andes Safarandes Asmara ${ }^{1}$, St Budi Waluya ${ }^{2}$, Hardi Suyitno ${ }^{3}$, Iwan Junaedi ${ }^{4}$ \\ 1,2,3,4 Mathematics Education, Postgraduate Program, Universitas Negeri Semarang, Indonesia \\ andes@ubpkarawang.ac.id
}

Article History: Received: 11 January 2021; Accepted: 27 February 2021; Published online: 5 April 2021

\begin{abstract}
The object of mind is something that must be taught by the teacher to the student in the form of learning, or we know that the teaching is the process ofinteraction between students, between students and teachers, and learning resources in the learning environment so that with it we as educators need to optimize thestudent's thought process so that students can be optimal for information. There are three sources of how students obtain optimization in the learning process, namely: intrinsic cognitive load (dependingon the difficulty level of amaterial), extraneous cognitive load (depending on the presentation of thematerial) and germane cognitive load (whichis imposed by teaching methods that lead to better learning outcomes). the results showed that the interactive element is well managed and extraneous cognitive load is suppressed to a mable so that it creates a large enough germane cognitive load.
\end{abstract}

Keywords: geometry, cognitive load theory

\section{Introduction}

Mathematics is the science of logic about shapes, arrangements, magnitudes and concepts-other related concepts with large numbers divided into three fields, namely algebra, analysis and geometry, or it can be said that mathematics is abstract ideas given the symbols are arranged hierarchically and reasoning is deductive, so learning mathematics is a high mental activity. Geometry is one of the important aspects of mathematics to learn and requires high mental activities but at the same time difficult for students to understand.

The lack of optimal understanding of students on geometry is evidenced by the national examination (UN) of junior high school students in Indonesia which shows that overall students are only able to answer the correct questions at most. With material details of the group numbers $39.71 \%$, algebra $51.24 \%$, geometry $42.27 \%$ and statistics and odds of 55.60\%. for West Java province, UN scores numbered $39.67 \%$, algebra 52.69\%, geometry $42.98 \%$ and statistics and opportunities by 56.12\% (PUSPENDIK, 2019), whereas this field of geometry is a field that must be studied by students in accordance with the curriculum 2013.

There are three reasons why geometry is studied. First, "geometry uniquely connects mathematics with the real physical word." Geometry associates mathematics with physical forms in the real world. For example, a beehive that is a representation of the sixth hexagonal arrangement. Second, "geometry uniquely enables ideas from other areas of mathematics to be pictured." Geometry allows other mathematical ideas to be visualized. For example, solving statistical problems using bar charts, pie charts, or various curves. Thethird "geometry nonuniquely provides an example of a mathematical system." In general geometry provides an example of a mathematical system, such as proving two parallel lines using a basic theorem of support.

The description above explains that matematika learn about order, about organized structures, mathematical concepts arranged hierarchically, structured and systematic, ranging from the simplest concepts to the most complex concepts. In mathematics the basic object studied is abstrak, so called a mental object, it is an object of thought.

The object of the mind is something that must be taught by the teacher to the student in the form of learning, or we know that the teaching is the process of interaction between students, between students and teachers, and learning resources in the learning environment (Permendikbud No. 103 Year 2014). In a learning environment that is the main goal is to makentu students to be able to learn. Learning is the process of changing the composition of knowledge that has been stored in memory through the reconstruction of old knowledge and constructing new knowledge. Knowledge reconstruction is usually done by thinking process.

The thought process according to Atkinson and Shiffrin (Glassman \& Hadad, 2009) there are two ways for students to think, namely by perception and encoding. Perception orinterpretation of information received using the senses and subsequent interpretation can be included in long-term memory through the working memory of our brain or we call encoding. But sometimes there are differences in the demands of the task or material that must be mastered by one's ability to master the demands, especially for mathematical concepts that precurs the precursing of certain material to understand it. This is known as cognitive load theory. It can be said that this theory of cognitive load is a psychological theory that explains the amount of burden that occurs in human cognitive due to tasks that exceed its capacity. Cognitive load includes three sources, namely: intrinsic cognitive load, extraneous cognitive load, and germane cognitive load (Plass, J.L., et al,2010).

Intrinsic cognitive load depends on the difficulty level of a material, but with good presentation techniques and does not complicate the understanding of learners it will be managed intrinsic cognitive load. Extraneous 
cognitive load depends on the presentation of the material. Whereas germane cognitive load is a relevant or beneficial burden imposed by teaching methods that lead to better learning outcomes. In learning, cognitive overload depends on the degree of difficulty of the material studied according to intrinsic cognitive load. If the material studied intrinsic cognitive load is high, then the learning design must be organized in such a way that extraneous cognitive load can be pressed to a maximum. This is in line with previous studies that stated thatthe process of defense ran based on cognitive load theoryis able to solve mathematical problems (Damayanti, 2013; Fitriyah, et al., 2014; Kristiana, 2015).

The process of managing cognitive load can go through the mathematical literacy process, because the indicators of the domain of the mathematical literacy process include formulating the situation mathematically, using mathematical concepts, factsprocedures and reasoning and interpreting, applying and evaluating mathematical results (OECD, 2017) and this is very relevant to geometry material. Based on the description that has been explained, this paper will describe how to manage mathematics learning based on students' cognitive load, with the objectives of research as follows: 1). describe cognitive load theory; 2). how to manage learning through mathematical literacy based on cognitive load theory on geometry material.

\section{Metodology}

\section{Research Design}

This research uses qualitative approach. Qualitative approaches are used because the study tries to describe and express, excavate and find broad points of view regarding students' cognitive load (Johnson and Crhistense, 2004). the type of research used is descriptive research. This descriptive study tries to illustrate how cognitive burdens are in geometry learning (Creswell, 2009).

\section{Population and Sample}

The population in this study was all students of SMPNegeri 2CiampelKarawang Regency in class VII, with the sample of the research being one class on geometry material in class VII with reference to the 2013 curriculum. geometry coverage in junior high school students in class VII is triangular and quadrilateral.

\section{Data Collection}

Instruments or supporting tools in this research are articles on the theory of cognitive load, the domain of mathematical literacy process issued by the OECD, KI and KD grade VII as a reference, geometry material at the junior high school level grade VII with triangular and quadrilateral materials and interview guidelines. Researchers in this study acted as the main instrument as well as data collectors, the observed learning is a learning activity carried out by math teachers as usual without any engineering or regulation. This activity is carried out so that the results obtained really illustrate the cognitive burden in learning geometry materials and how efforts to manage cognitive load through mathematical literacy process.

\section{Data Analysis}

The data analysts arein through several steps. The steps in this study include: preparation (completeness of instruments), domain analysis of mathematical literacy process and cognitive load components, data collection (observation and interview), data processing, and report writing. All instruments analyzed by researchers to be able to answer questions so that the final results are expected to provide examples of geometric teaching materials design through a mathematical literacy process based on cognitive load.

\section{Results \& Discussion}

Based on the purpose of the research mentioned,the authors triedtodiscuss one byone, startingfromthe description of the theory of cognitive load and how the efforts to manage the theory of cognitive load in mathematics learning with geometric materials and the impact of the application of this theory to geometry learning.

\section{Cognitive Load Theory}

Cognitive load theory is a psychological theory that tries to explain that there is a difference in demands between the task and the ability of a person to master these demands so that here it is explained how our working memory efforts in processing information / tasks given at one time so that learning outcomes can be predicted (Moray, 1979; Cooper, 1990; Plass., Moreno., sweller, 2010). So pthere is a basic, cognitive load theory asserting that learning can be hampered when working memory capacity is exceeded in learning tasks.

Working memory works for the thought process. Berpikir is one of the abilities that teachers should teach students. One theory that discusses how human thought processes were put forward by Atkinson and Shiffrin in 1968 (Glassman\&Hadad, 2009). These two cognitive psychology experts managed to explain how human 
thinking devices and processes that occur clearly, logically and simply. Their theories are both known as information processing theories.

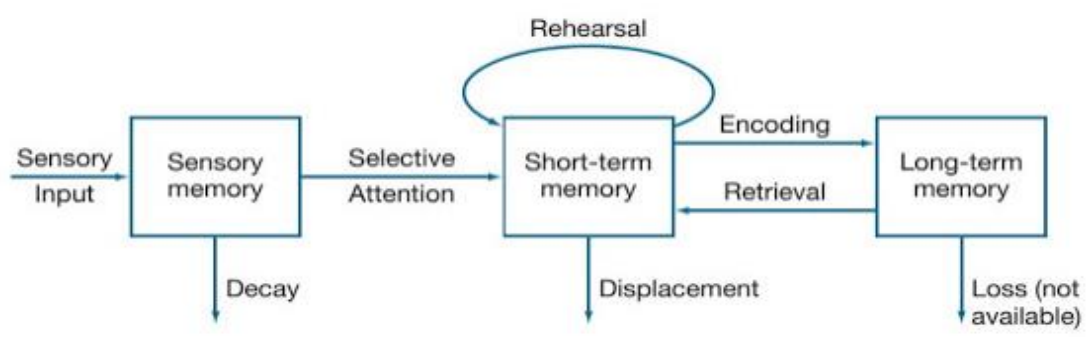

Figure 1: Atkinson and Shiffrin Information Processing Theory Model

Speaking of a general thought process, there are many things involved in that process from the beginning. Among them is the role of memory or memory as well as information sharing. It should be necessary to know the concept of memory model and information processing in order to further analyze a thought process. Before exploring more about these two things, it is necessary to introduce first the concept that is also related to both. That is, the concept of perception. Suharnan (2005) mentions perception is a process of using knowledge that has been possessed (stored in memory) to detect or obtain and interpret the stimulus received by sensory devices such as, eyes, ears and nose. Based on this understanding, it can be said that perception is the process of interpreting information received using a sense tool.

There are 3 relevant aspects in perception related to human cognition, namely, the recording of the senses, pattern recognition and attention. The first aspect, the recording of the senses is a memory system designed to store a record of the information received by receptor cells. Sensory recording is also known as sensory memory that is distinguished into two kinds, namely, iconic sensory recording system against visual information, images and concrete and echonic objects that is the sensory recording system against information in the form of sound

The second aspect, pattern recognition is the process of transformation and organizing information that is still abusive in order to have a certain meaning or meaning. This aspect is deeper than just storing the information entered through receptors, in other words it can also be said that the aspect of pattern recognition is an effort to organize incoming information in accordance with the characteristics that stand out to be placed according to the type.

Attention is the third aspect, which is defined as the process of centralizing mental activity or the process of concentration of the mind by ignoring other unrelated stimuli. This activity requires concentrating the concentration of the mind on the things that stand out from an information and works intensely on the information by ignoring the uncons relates.

The initial receiver of information on this sense is referred to as sensory memory. According to the study, information from vision can only last less than a second in sensory memory, while information from hearing can last three to four seconds. If attention is not paid to such information then they will be lost. But if attention is given then the information will be forwarded to short-term memory which can retain information from 15 seconds to 30 seconds (Driscoll, 2005). Information will be lost if we do not repeat the attention to him. However, if a repeat is performed then the information can be passed on to long-term memory.

The researchers state that long-term memory can store information for a very long time, depending on its use as revealed by Baddeley (2012) mentioning working memory is responsible for processing information and following up on such information. If the technique for passing information on to long-term memory is through repetition, we call it the process of memorizing or remembering.

The second way to pass on information to long-term memory is to understand (encoding). The point is to connect the new information with the various old information that we have (stored in the previous long-term memory). This second way is believed to make information more durable in our memory. In addition, by understanding then all the information will be more useful in the application of daily life.

Various information stored in long-term memory, can at any time be called by short-term memory if we need it (for example when facing certain problems). Miller (Nursit, 2015) says working memory can only store about seven items or pieces of information at a time. When processing information (organizing, showing differences, and comparing), humans can manage only two or three items of information simultaneously, depending on the type of processing required (Kirschner, Sweller, \& Clark, 2006). Until now experts have not been able to determine exactly what human long-term memory storage capacity is. It is therefore said that our long-term memory capacity is unlimited.

Based on the description above it is clear that the theory of cognitive load is trying to optimize the tasks that come in on long-term memory so that learning can be optimal. Cognitive load theory can be caused by three sources, namely: intrinsic cognitive load, extraneous cognitive load, and germane cognitive load (de Jong, 2009; Plass, J.L., et al,2010; Sweller 2010). Intrinsic cognitive load is related to the inherent characteristics of the 
content to be studied,Intrinsic cognitive load in learning is caused by two things namely, element interactivity and elements isolated / interacting element (Artino, 2008). The second is extraneous cognitive load is a load caused by instructional materials used to present content, and germane cognitive load refersto the load imposed by the learning process.

In other words intrinsic cognitive loads and extraneous cognitive loads are cognitive loads associated with elements of interactivity in learning whereas cognitive loads are cognitive burdens associated with mental effort relevant to understanding. Intrinsic cognitive loads and extraneous cognitive loads tend to interfere in learning whereas cognitive loads tend to be supportive in learning (Lin and Lin, 2013). High extraneous cognitive load in learning results in poor student performance while germane high cognitive load results in better student performance (Jong, 2010).

Based on the exposure of cognitive load theory, it can be concluded that the cognitive load of students contains three types of cognitive processing during learning, namely:

1. intrinsic cognitive load is a burden of thought experienced by students during learning due to the demands of content.

2. germane cognitive load is a burden of thought experienced by students during learning caused by the need to integrate new information with previous knowledge.

3. extraneous cognitive load is a burden of thought experienced by students during learning caused by the work of the mind that is not in accordance with the objectives of learning (Clark et al, 2006).

\section{Managing Learning Through Mathematical Literacy Based on Cognitive Load}

To be able to see how to manage learning through mathematical literacy based on cognitive load, especially geometry material in grade VII with triangular and quadrilateral concepts, then the analysis of the domain cognitive load and indicators domain literacy process, observation on the learning process and interviews in students so that it can conclude how efforts to manage the learning. Here are some steps from the research done:

1. Mathematical literacy and cognitive load domain analysis based on sources and interviews and observations

\section{Mathematical literacy}

Domain mathematical literacy process which is divided into three indicators with a range of different activities on each indicator. Here are three indicators of the process domain and the activities in each of its indicators, in table 1:

Table 1. Mathematical Literacy Process Domain Indicators

Indicator
Formulating the
situation
mathematically.
contexts and identify significant variables.
2. Recognize mathematical structures (including regularity,
relationships and patterns) in problems or situations.
3. Simplify a situation or problem to make it accept mathematical
analysis.
4. Identify the constraints and assumptions behind mathematical
modeling and simplifications collected from context.
$5 . \quad$ Represent the situation mathematically, using appropriate variables,
symbols, diagrams and standard models.
6. Represent the problem in different ways, including arranging it
according to mathematical concepts and making precise assumptions.
7. Understand and explain the relationship between the specific
language of the problem context and the symbolic and formal language
needed to mathematically represent it.
8. Translate the problem into a mathematical or representational
language.
9. Identify aspects of the problem that correspond to known problems
or mathematical concepts, facts or procedures.
10. Use technology (such as spreadsheets or list facilities on graphing
calculators) to describe mathematical relationships inherent in contextual
problems.




\begin{tabular}{|c|c|}
\hline Indicator & Activities \\
\hline \begin{tabular}{l}
\multicolumn{1}{c}{ Using } \\
mathematical \\
concepts, facts, \\
procedures, and \\
reasoning
\end{tabular} & $\begin{array}{l}\text { 1) Selecting the appropriate model from the list. } \\
\text { 1. Designing and implementing strategies to find mathematical } \\
\text { solutions. } \\
\text { 2. Use mathematical tools, including technology, to help find the right } \\
\text { solution or forecast. } \\
\text { 3. Apply facts, rules, algorithms and mathematical structures when } \\
\text { searching for solutions. } \\
4 . \quad \text { Manipulating numbers, graphical and statistical data and } \\
\text { information, algebraic expressions and equations, and geometric } \\
\text { representations. } \\
\text { 5. Make mathematical diagrams, graphs and constructions and extract } \\
\text { mathematical information from them. } \\
6 \text {. Use and switch between different representations in the process of } \\
\text { finding a solution. } \\
\text { 7. Make generalizations based on the results of applying mathematical } \\
\text { procedures to find solutions. } \\
\text { 8. Reflect mathematical arguments and explain and justify } \\
\text { mathematical results. } \\
\text { In addition to the activities listed above, the following activities have been } \\
\text { added to PISA-D: } \\
\text { 1) Do a simple calculation. } \\
\text { 2) Draw simple conclusions. } \\
\text { 3) Choose the right strategy from the list. }\end{array}$ \\
\hline $\begin{array}{l}\quad \text { Interpret, apply } \\
\text { and evaluate } \\
\text { mathematical } \\
\text { results. }\end{array}$ & $\begin{array}{l}\text { 1. Interpret mathematical results back into a real-world context. } \\
\text { 2. Evaluate the fairness of mathematical solutions in the context of real- } \\
\text { world problems. } \\
\text { 3. Understand how the real world affects the results and calculations of } \\
\text { mathematical procedures or models to make contextual assessments of how } \\
\text { results should be adjusted or applied. } \\
4 \text {. Explain why mathematical results or conclusions, or not, make no } \\
\text { sense given the context of the problem. } \\
5 \text {. Understand the level and limits of mathematical concepts and } \\
\text { mathematical solutions. } \\
6 \text {. Criticize and identify the boundaries of the model used to solve a } \\
\text { problem. } \\
\text { In addition to the activities listed above, the following measures have been } \\
\text { added to PISA-D: } \\
\text { 1) evaluate mathematical results in context. }\end{array}$ \\
\hline
\end{tabular}

$(\mathrm{OECD}, 2017)$

\section{Cognitive Load Theory}

Consists of three components, namely:

\section{Intrinsic cognitive load}

Intrinsic cognitive load is determined by the degree of complexity or difficulty of the material being studied (Sweller \& Chandler, 1994). Intrinsic cognitive load cannot be manipulated because it is already a character of interactive elements in a material, so it is fixed (constant) (Sweller, et al. 2011). Material that intrinsically has a heavy load, if presented properly, then the cognitive processes in working memory will be able to run smoothly. Conversely, although the intrinsic load on a material is light, but if the presentation is not good, then the cognitive processes of students in working memory will run slowly or stop working

Intrinsic cognitive load, determined by the level of complexity of the information or material being studied. An important factor in teaching a material is understanding the emergence of interactivity elements, namely a number of elements that must be jointly processed in working memory under instructions. The element of interactivity is fixed because it is intrinsically possessed by all the material that must be studied and cannot be changed. This element appears in learning caused by elements that must be processed simultaneously between elements in the material or in other words determined by the interaction between important elements of 
information used to understand the material (Kalyuga, 2011).

Based on the observation and interview of interactivity elements in geometry learning is related to the difficulty of imagining how to determine the position of a point, line, and field. Students must be able to represent and interpret the position of a point, line, and field so that then the student is able to determine the distance from the point, line, and field. Students in learning geometry do have difficulty in imagining. The difficulty of imagining resulted in students being less able to configure in terms of point of view, introduction of form and position, and representation from a point of view (Gal and Linchevski, 2010).

\section{Extraneous cognitive load}

Unlike instrinsic cognitive load, extraneous load can be manipulated. extraneous cognitive load is determined by the technique of presenting the material (Sweller \& Chandler, 1994). So this extrinsic burden is related to how to interpret a material in a learning. A good way of presenting the material, namely if the delivery is systematic, practical, effective and interesting. Systematic here means that the material is delivered according to the basic competencies (KD) that exist and in the correct order so that students can connect the material with each other well. Practical is a matter to be considered in the delivery of materials, the practical purpose here the material is delivered neatly, appropriately, and not excessively. Effective in this case has the understanding that the presentation of ametry must be tailored to the objectives to be achieved in learning. While interesting means that the presentation of the material is done by methods that make students happy, and motivated to follow the learning, for example the presentation is done by displaying with images, colors, and sound audio so that it makes students feel more interested in the material

Extraneous cognitive load is determined by material presentation techniques and things related to factors that must be minimized in learning, such as the use of confusing teaching materials, noise, and the appearance of computer media that is too much animation.

Extraneous cognitive load in geometry material learning is also caused by some students who are rowdy or crowded. Rowdy or crowded students are students who do not pay attention as the teacher explains. The rowdy or crowded classroom situation is a result of the instructional design of the teacher who does not include the entire student. The teacher's learning is dominant only in some students (tending to be diligent and obedient students) so that some students will be crowded and rowdy themselves. This situation is also called a splitattention situation (Kalyuga, 2011). Students who pay attention to learning will share their attention between listening to the teacher's explanation and the noise caused by some students. So that the crowded learning conditions must be suppressed as low as possible so that students can focus their attention on learning. The extraneous cognitive burden in learning should be suppressed as low as possible (Gerven, Paas, et al., 2002).

Extraneous cognitive load in this study can be seen from the results of interviews that mention that some students, especially those who sit not too in front sometimes feel disturbed by rowdy students, always nice to chat with their classmates so that sometimes the attention to focus on the material is split, plus sometimes the teacher's voice is less audible for students who feel sitting in the back and there are some parts of the teacher's explanation that are too quick.

\section{Germane cognitive load}

Germane cognitive load is a cognitive burden caused by cognitive processes that relavan with the understanding of the material being studied Germane cognitive load means that the memory of students can not organize, construct, codify, elaborate or integrate the material being studied as well-stored knowledge in longterm memory. Germane cognitive load is a relevant or beneficial burden imposed by teaching methods that lead to better learning outcomes. In other words, germane cognitive load can be an effort to build schemes and automation in learning. germane cognitive load is a burden caused by students' efforts to process and understand the material (Sweller, Ayres, and Kalyuga, 2011). Therefore, in the learning process german cognitive load must be improved and to be more effective it needs facilities to bridge the learning (Jong, 2010; Lin and Lin, 2013).

Germane cognitive load in geometry material learning is caused by the teacher's efforts when explaining using the help of the Cabri 3D application program. The use of cabri 3D application program aims to make it easier for students to understand the position of points, lines, and fields in building space. The use of computer programs relevant to the delivery of materials related to point, line, and field position makes it easier for students. The results for german cognitive load can be seen from the results of interviews that most respondents stated that by using the facilities Cabri 3D. some students stated that students feel able to imagine how the position of points, lines, and fields in building space especially for triangular and quadrilateral fields. Moreover, those who have a visual and auditory type of learning style. As stated (Wardani et al, 2018) that for students with visual and audio learning type will be very effective in the learning process by using facilities (e-learning) in this case specifically Cabri 3D. 


\section{Syntax that can be used in learning through mathematical literacy based on cognitive load}

After the analysis of the mathematicalliteracy process, then analyze the cognitive load components as well as the data of interviews and observations on mathematics learning. So in the results of the analysis of researchers how the learning process can be done in the classroom through mathematical literacy based on cognitive load on the concept of triangles and quadrilaterals, as described in table 2.

Table 2. Cognitive Load-Based Mathematical Literacy Learning (LMBK)

\begin{tabular}{|c|c|}
\hline $\begin{array}{c}\text { Sintak } \\
\text { Learning Models }\end{array}$ & Learning Activities \\
\hline Matematization & $\begin{array}{ll}\text { 1. } & \text { Identify issues by context } \\
\text { 2. } & \text { Analyze and make assumptions } \\
\text { 3. } & \text { Apply modeling } \\
\text { 4. } & \text { Translate into math language }\end{array}$ \\
\hline Application & $\begin{array}{l}\text { 1. Implementing and designing strategies } \\
\text { 2. Applying fact (modeling) or information excavation to } \\
\text { construct conceptsMake generalizations }\end{array}$ \\
\hline $\begin{array}{l}\text { Meaning and } \\
\text { Reflection }\end{array}$ & $\begin{array}{l}\text { 1. Re-examine the generalization results } \\
\text { 2. Analysis of whether conclusions can be relevant to the problem } \\
\text { 3. Identify the suitability of the model used to troubleshoot } \\
\text { 4. Reflecting and concluding }\end{array}$ \\
\hline
\end{tabular}

\section{Conclusions}

Knowledge of how humans think, making their memories enter into long-term memory so that we can say as a learning process. An understanding of human cognitive architecture in acquiring, processing and storing information as a new knowledge is the basis for explaining why some instructional procedures work while others fail. Cognitive Load Theory emphasizes methods to help students achieve optimal abilities based on how the cognitive system works because working memory has limited capacity in processing a certain amount of information together. The management of learning based on cognitive through mathematical literacy results in a stage of the learning process that can be done in the classroom to optimize the improvement of students' abilities.

This research has not yet come to examine the instructional impact of learning management through mathematical literacy process based on cognitive load, so for follow-up researchers try to conduct effectiveness test to see the impact of learning management through mathematical literacy process based on cognitive load on geometry material, especially triangle and quadrilateral.

\section{References}

1. Ayres, P. (2006a). Impact of reducing intrinsic cognitive load on learning in a mathematics domain. Applying cognitive psychology, 20, 287-298. https://doi.org/10.1002/acp.1245

2. Ayres, P. (2006b). Using subjective measures to detect variations of intrinsic load within problems. Learning and Instruction, 16, 389-400. https://doi.org/10.1016/j.learninstruc.2006.09.001

3. Ayres, P. (2013). Can the isolated-elements strategy be improved by targeting points of high cognitive load for additional practice? Learning and Instruction, 23, 115-124. https://doi.org/10.1016/j.learninstruc.2012.08.002

4. Brünken, R., Seufert, T., \& Paas, P., (2010). Measuring cognitive load. In J. L. Plass, R. Moreno, and R. Brünken(Eds.), Cognitive load theory and research in educational psychology (pp. 181-202). New York, NY: CambridgeUniversity Press.https://doi.org/10.1007/978-1-4419-8126-4_6

5. Clarke, T., Ayres, P., \& Sweller, J. (2005). The impact of sequencing and prior knowledge on learning mathematics through spreadsheet applications. Educational Technology, Research and Development, 53, 15-24. https://doi.org/10.1007/BF02504794

6. DeLeeuw, K. E., \& Mayer, R. E. (2008). A comparison of three measures of cognitive load: evidence for separable measures of intrinsic, extraneous, and germane load. Journal of Educational Psychology, 100, 223-234. https://doi.org/10.1037/0022-0663.100.1.223

7. Galy, E., Cariou, M., \& Mélan, C. (2012). What is the relationship between mental workload factors and cognitive load types? International Journal of Psychophysiology, 83, 269-275. https://doi.org/10.1016/j.ijpsycho.2011.09.023

8. Huang J. -C (Ed.) (2012). Elementary Mathematics Textbook, 12, Tainan, Taiwan, Nani Press.

9. Huang, Y.-H., \& Shie J.-T (2016). The Comparison of Two Mathematics Problem-Solving Strategies of Line-Diagram Representations on Learning Achievements. Bulletin of Educational Psychology, 47(4), 581-601.https://doi.org/10.6251/BEP.20150603 
10. Kalyuga S. (2015). Instructional guidance: A cognitive load perspective, Charlotte, NC, USA: Information Age Publishing.

11. Kester, L., Kirschner, P. A., \& van Merriënboer, J. J. G. (2004a). Information presentation and trouble shooting in electrical circuits. International Journal of Science Education, 26(2/6), 239-256. https://doi.org/10.1080/69032000072809

12. Kester, L., Kirschner, P. A., \& van Merriënboer, J. J. G. (2004b). Just in time presentation of different types of information in learning statistics. Instructional Science, 32, $233-252$. https://doi.org/10.1023/B:TRUC.0000024191.27560.e3

13. Kester, L., Kirschner, P. A., \& van Merriënboer, J. J. G. (2006). Just-in-time information presentation: Improving learning and troubleshooting skill. Contemporary Educational Psychology, 31, 167-185. https://doi.org/10.1016/j.cedpsych.2005.04.002

14. Kester, L., Paas, P., \& van Merriënboer, J. J. G. (2010). Instructional control of Cognitive Load in the Design of Complex Learning Environments., In J. L. Plass, R. Moreno, \& R., Brünken (Eds.), Cognitive load theory andresearch in educational psychology (pp. 109-130). New York, NY: Cambridge University Press.

15. Lee, Y.-C. (2013). A Study of Line Segment Diagram Representation on Reference Quantity Problem Solving Performancefor Sixth Grader (Unpublished master's thesis), National Pingtung University of Education, Pingtung, Taiwan.

16. Leppink, J., \& van den Heuvel, A. (2015). The evolution of cognitive load theory and its application to medical education. Perspectives on Medical Education, 4, 119-127. https://doi.org/10.1007/s40037015-0192-X

17. Leppink, J., Paas, F., van der Vleuten, C. P. M., Van Gog, T., \& van Merriënboer, J. J. G. (2013). Development of aninstrument for measuring different types of cognitive load. Behavior Research Methods, 45(4), 1058-1072. https://doi.org/10.3758/s13428-013-0334-1

18. Leppink, J., Paas, F., van Gog, T., van der Vleuten, C. P. M., \& van Merriënboer, J. J. G. (2014). Effects of pairs ofproblems and examples on task performance and different types of cognitive load. Learning and Instruction,30, 32-42. https://doi.org/10.1016/j.learninstruc.2013.12.001

19. Mayer, R. E., \& Moreno, R. (2003). Nineways to reduce cognitive load in multimedia learning. Educational Psychologist, 38, 43-52. https://doi.org/10.1207/S15326985EP3801_6

20. Mayer, R., \& Moreno, R. E. (2010). Techniques that reduce extraneous cognitive load and manage intrinsic cognitive load during multimedia learning. In J. L. Plass, R. Moreno, \& R. Brünken (Eds.), Cognitive load theory andresearch in educational psychology. (pp. 131-152). New York: Cambridge University Press. https://doi.org/10.1017/CBO9780511844744.009.

21. OECD. (2017). Draft PISA For Development Assessment And Analytical Frameworkdownloaded from website https://www.oecd.org/pisa/pisaproducts/PISAD\%20Assessment\%20and\%20Analytical\%20Framework\%20Preliminary\%20Version.pdf accessed on 03 Desember 2018.

22. Pollock, E., Chandler, P., \& Sweller, J. (2002). Assimilating complex information. Learning and Instruction, 12, 61-86. https://doi.org/10.1016/S0959-4752(01)00016-0

23. Renkl, A., \& Atkinson, R. K. (2010). Learning from worked-out examples and problem solving. In J. Plass, R. Moreno, \& R. Brünken (Eds.), Cognitive load theory and research in educational psychology (pp. 91-108). NewYork: Cambridge University Press. https://doi.org/10.1017/CBO9780511844744.007

24. Sweller, J. (1988). Cognitive load during problem solving: effects on learning. Cognitive Science, 12, 257-285. https://doi.org/10.1207/s15516709 $\operatorname{cog} 1202 \_4$

25. Sweller, J. (2010a). Element interactivity and intrinsic, extraneous, and germane cognitive load. EducationalPsychology Review, 22, 123-138. https://doi.org/10.1007/s10648-010-9128-5

26. Sweller, J. (2010b). Cognitive load theory: recent theoretical advances. In J. L. Plass, R. Moreno, and R. Brünken(Eds.), Cognitive load theory and research in educational psychology (pp. 29-47). New York, NY: CambridgeUniversity Press. https://doi.org/10.1017/CBO9780511844744.004

27. Sweller, J., Ayres, P., \& Kalyuga S. (2011) Altering Element Interactivity and Intrinsic Cognitive load, Cognitive load theory (pp. 203-218). New York, NY: Springer-Verlag.

28. Wardani, D.N., et al. (2018). Daya Tarik Pembelajaran di Era 21 dengan Blended Learning. Jurnal Kajian Teknologi Pendidikan, 1(1), 13-18.

29. Wong, A., Leahy, W., Marcus, N., \& Sweller, J. (2012). Cognitive load theory: The transient information effect and e-learning. Learning and Instruction, 22, 449-457. https://doi.org/10.1016/j.learninstruc.2012.05.004 